to rest at night, and to whom the other males are subservient. Dr. Schaller also encountered numbers of solitary males. Each group of gorillas sticks to an area of 10 to 15 square miles of forest, but since the area may be occupied by more than one group Dr. Schaller prefers not to classify the gorilla among those primates which are strictly territorial in their habits. Fooda vegetarian diet-is abundant, and Dr. Schaller could find no evidence that the animals ever eat meat, a negative observation which he established by a very extensive analysis of the animals' dung. Nor do they drink water directly-they presumably take in sufficient fluid with the succulent herbage they eat. Sexual activity appears to play a very inconspicuous part in their lives, and they also rarely come to blows-or teeth-even though displays of dominance on the part of the big males, especially the performance of chest beating, seem very terrifying. According to Dr. Schaller predation, other than by man, is a minor factor in determining the life cycle, and disease is the major cause of death.

Some of the matters described by Dr. Schaller seem hardly to deserve the amount of space he has accorded them-for example, his discussion of variations in nest building, and of the animals' excretory habits. And some of the quantitative data he provides gives a spurious air of importance, through figures, to the matters discussed. It is, for example, odd to read that the average walking speed of a gorilla is 532.7 feet per hour, with a standard deviation of 452 feet. It would surely have been enough to say that in the course of an hour a gorilla usually covers anything between 100 and 1,800 feet, or whatever figures he chose to give us. It is even stranger to read that " in a total of 2,451 nests . . .99 per cent contained dung ", as opposed to a brief sentence that the animals always foul their nests. Points like these detract from what is otherwise a work of scholarship, and suggest that the author lacks a sense of intellectual priorities.

Dr. Schaller's careful field study provides no new generalisations about primate behaviour. At the same time certain matters, for example, the significance of male dominance in relation to the presence of solitary males and in relation to sexual activity, seem to have been treated in accordance with views which the author accepted before going to Africa rather than by a critical analysis of the data as they revealed themselves. But let us be fair. Dr. Schaller did not set out to provide us with generalisations about primate behaviour, and we should be grateful for the new facts he has given us. So far as the Fauna Preservation Society is concerned, it would certainly be true to say that we now have available the kind of information on which to base a policy for the conservation in the wild of what many regard as Man's most interesting cousin.

S. ZUCKERMAN

A photograph of gorillas from Dr. Schaller's book is on plate 1.

\title{
Henderson's Dictionary of Biological Terms. By J. H. Kenneth. Oliver and Boyd, 63s.
}

This standard work used to be called "A Dictionary of Scientific Terms," but as its scope since its first edition in 1920 has covered only the biological sciences, it was rightly thought better to change the name for this eighth edition. It is strictly biological, and not in any way a natural history dictionary, with the bias towards the laboratory and museum, though first-class within this restricted biological ambit. It has, for instance, no definition of bog, heath or fen, and it is perhaps unreasonable to expect the word " conservation" to appear, though one hopes that it will not be long before biologists do not merely peer out of the laboratory at their disappearing subject-matter but stride out and help to save it.

R. S. R. FITTER 